NOTAS 



\title{
DR. D. FELIPE RUIZ MARTÍN, IN MEMORIAM
}

\author{
LUIS MARÍA BILBAO BILBAO \\ Universidad Autónoma de Madrid \\ EMILIANO FERNÁNDEZ DE PINEDO \\ Universidad del País Vasco
}

JOSÉ ANTONIO ÁLVAREZ VÁZQUEZ

Universidad Autónoma de Madrid

Se llega a veces a concebir la ilusión de que ciertas gentes de nuestro entorno, las más allegadas, se verán libres del ineludible término natural de la vida. Tras más de treinta años de convivencia casi cotidiana con don Felipe -siempre le llamábamos así-, su persona y magisterio acabaron por formar parte de nuestro paisaje más familiar, y hoy nos es doloroso reconocer que nos engañábamos al alimentar tamaña ilusión. No así él. Don Felipe no se dejó confundir, fue muy consciente de las previsibles consecuencias de su enfermedad, y lo declaraba sin ambages y sin dejarse embaucar por cuantos porfiábamos en inducirle ánimos con disimulos piadosos. Falleció en Madrid el pasado 27 de Enero y fue enterrado el día 29 en Palacios de Campos, provincia de Valladolid, donde naciera hace 88 años.

El iter academicum del profesor Ruiz Martín discurrió por una senda bastante común en una generación mediatizada por la guerra civil. Realizó los estudios de enseñanza secundaria en una institución privada, el Colegio de los Marianistas de la ciudad de Valladolid, como era norma en toda familia acomodada de entonces. La enseñanza superior la cursó en la Universidad de Valladolid, donde se matriculó en 1930 para seguir los estudios de la Licenciatura de Filosofía y Letras, especialidad de Historia y Geografía, en la que obtuvo el año 1935 el premio extraordinario de final de carrera. No es seguro que fuera la Historia Moderna su preferencia vocacional originaria. Curiosamente, las primeras publicaciones juveniles, de época estudiantil, calificadas por él mismo de «apuntes eruditos», versaron sobre Arte y Arqueología. Su inclinación hacia la Historia Moderna se la atribuía, como muchas veces nos lo recordó, al influjo que sobre él ejerciera el magisterio y personalidad del profesor D. Julián María Rubio, mentor de su tesis doctoral. Ésta fue defendida el año 1943 en la Universidad de Madrid, tal y como entonces era costumbre por parte de quienes pretendían hacer carrera académica en la Universidad. La tesis versó sobre las relaciones diplomáticas entre Polonia y España en el siglo XVI y obtuvo la máxima 
calificación, sobresaliente cum laude, coronada luego con premio extraordinario de doctorado. Al término de este primer periplo académico estaban claros los propósitos del futuro Profesor Ruiz Martín: ser catedrático de Universidad en el ámbito de la Historia Moderna. Plasmarlos, sin embargo, sería algo enrevesado y diferiría del diseño pergeñado. Llegaría a la Universidad pasando por la Enseñanza Media, y no obtendría una cátedra de Historia Moderna, sino de Historia Económica.

Al poco de finalizar la guerra fue nombrado profesor ayudante en la Facultad de Letras de Valladolid, puesto a la sazón literalmente de meritorio. Las limitadas expectativas, de todo orden, que las circunstancias de posguerra brindaban a cuantos en España aspiraban a hacer carrera universitaria empujaron a toda una generación de futuros profesores de Universidad a transitar primero por la Enseñanza Media. Don Felipe no fue en este sentido una excepción. En 1941 ganó por oposición la cátedra de Geografía e Historia del Instituto Jorge Manrique de Palencia, plaza que ocuparía hasta 1961, compaginándola con el cargo de Inspector de Enseñanza Media en Valladolid y la edición de manuales didácticos de Historia, así como de trabajos de orientación pedagógica para el bachillerato. Pero la dedicación afanosa a estas labores no le haría renunciar a sus más anheladas aspiraciones, pues frecuentó el Archivo de Simancas, manantial permanente de sus investigaciones, culminó y defendió su tesis doctoral, comenzó a publicar en las revistas españolas entonces más prestigiosas, y a concurrir a oposiciones a cátedra de Historia Moderna, en las que tropezó siempre con el obstáculo infranqueable y arbitrario de quienes controlaban el sistema. En esto, don Felipe tampoco fue un caso único en la Universidad española de posguerra.

El cambio de terreno historiográfico, de la Historia Moderna general, más en concreto política o diplomática, donde hasta entonces se habían centrado empeños y publicaciones, hacia la Historia Económica, se inició a mediados de los años 40, se consolidó en el siguiente decenio y quedó consagrado en 1961. Las razones de este giro nos las pormenorizó don Felipe en más de una ocasión. En el origen estaba su personal insatisfacción con una historia cuyos principales, casi únicos, argumentos explicativos se ceñían reductivamente a lo político. Y luego, la influencia de la literatura que mejor representaba la tradición de la escuela histórica alemana y la renovación de la francesa desde la revista Annales. La lectura de Carlos V y sus banqueros de Carande, cuyo primer tomo hacía su aparición en 1943, y de $L a$ Méditerranée et le monde méditerranéen à l'époque de Philipe II de Braudel, publicada en 1946, significó el descubrimiento de la luz que apuntaba la salida del túnel de la desazón historiográfica. La estancia en París entre 1953 y 1957 como attaché al Centre National de la Recherche Scientifique de Francia, por invitación expresa y bajo la dirección del que siempre reconocerá como «el maestro», Fernand Braudel, lanzó definitivamente a Don Felipe al campo historiográfico de la Historia Económica, cultivándola al modo y estilo renovado de los Annales. No sin razón, el Profesor Ruiz Martín ha sido conocido como el más distinguido representante espa- 
ñol de la escuela francesa. El reconocimiento es correctísimo siempre que se entienda que lo fue de una de las fases de dicha escuela, la primera, en la que alcanzó su cénit de creatividad e influencia: la época en la que el magisterio de Braudel, rodeado de discípulos reclutados en distintas regiones mediterráneas, marcaba temas, tiempos y métodos, con miras a culminar la obra por él empezada. Era bastante evidente lo que, en este programa, iba a ser asignado al investigador español por parte del maestro francés. Entre ambos se acabaría anudando una profunda amistad, y la fidelidad del discípulo se dilatará más allá de la muerte del maestro. A cuantos quisieron oírle, Don Felipe pudo contar emocionado el estremecimiento que experimentó cuando, hace muy pocos años, visitaba la tumba de Braudel en el cementerio parisino de Père Lachaise.

La oportunidad de una cátedra de Historia Económica en la Facultad de Ciencias Económicas de la entonces Universidad de Bilbao acabó por decidir la suerte académica del Profesor Ruiz Martín, consagrándolo como historiador económico. Fue el primer catedrático de nuestra disciplina en España, y sería el único durante bastante tiempo. Los años de estancia en Bilbao (1961-1973) constituyen sin duda su etapa historiográficamente más fértil y creativa. La apreciación no es gratuita. Se avala con el propio juicio de don Felipe. En los curricula abreviados en que consignaba sus publicaciones más significativas, se decantaba por las de esta época. Pero la fecundidad de esta etapa no es comprensible sin los años previos de gestación. En la anterior se alternaron estancias en París con campañas de investigación en Simancas y en el Archivo de los Ruiz, metáfora peripatética, diríamos, que expresa la concepción y práctica de un oficio que, a juicio de don Felipe, debía combinar los nuevos planteamientos teóricos con una información documental a ellos adecuada. De esta época destacan sus dos libros y la monografía sobre la banca en España. Uno de los libros permanece desafortunadamente inédito -sus galeradas aseguramos que existen-, Les alums espagnols, cuyo significativo subtítulo reza Index de la conjoncture économique de l'Europe au XVI ${ }^{e}$ siècle (1960). El otro, Lettres marchandes échangés entre Florence et Medina del Campo (1965), viene precedido de un amplio prólogo que sigue siendo una excelente introducción a la historia económica de Castilla en el siglo XVI, como lo certifica el haber merecido su reedición con el título de Pequeño capitalismo, gran capitalismo. Simón Ruiz y sus negocios en Florencia (1990). «La banca en España hasta 1782» constituye su colaboración a una obra que hizo época, El Banco de España: una Historia Económica (1970); en ella reconstruía, por vez primera y en una colada, la historia de la banca española, no sólo castellana, desde la Edad Media hasta la fundación del Banco de San Carlos. Pero tan importantes y destacables como estas tres obras, en algunos casos puede que más, son sus artículos de revista y las ponencias o comunicaciones presentadas en los Congresos Internaciones de Historia Económica o en las Settimane del Instituto Internazionale di Storia Economica «F. Datini», de cuyo comité científico, plagado de figuras de talla mundial y presidido por Braudel, será miembro desde 1969. 
Sus investigaciones se centraron durante esta época en el tema de las finanzas, pero desbordaron también este campo con similar eco y éxito historiográficos que aquéllas. Sus trabajos sobre demografía histórica, basados en nuevas fuentes que él descubrió -porque buscó-, los relativos a la ganadería o a la industria textil castellana, constituyeron, y aún lo siguen siendo, piezas de ineludible referencia para el conocimiento de la economía castellana en la primera Edad Moderna. Pero, a no dudarlo, el núcleo central de sus investigaciones se refirió a las finanzas, tanto públicas como privadas, de dicha Edad Moderna, contempladas con enfoque integrador. Él mismo lo confesó: «...a las finanzas públicas, ampliamente concebidas, he dedicado mis empeños, consciente de que no podía dejar de lado, porque estaban engarzadas, las finanzas privadas». Fue un historiador de las finanzas y no estrictamente de la Hacienda, como a veces se ha malentendido. Nos lo reiteraba sin cesar y nos lo legó por escrito: «son cosas distintas, incomparablemente más complicada la primera que la segunda». En aquélla destacó hasta convertirse en una auténtica autoridad mundial. Sintomáticamente, en 1968 fue nombrado miembro del Consejo de Redacción de la International Review of the History of Banking. Todo un signo de reconocimiento internacional como historiador económico de prestigio, especialista en el ámbito de las finanzas, uno de los sectores económicos más espinoso y rebelde a su comprensión en nuestra disciplina.

Hay, además, dos temas historiográficos en los que brillaron sus aportaciones durante esta etapa, y ello tanto por lo que expresamente expuso como por lo que insinuó y con ello alentó. Uno fue la datación de la coyuntura económica castellana de los siglos XV al XVIII; el otro, las relaciones entre el mundo urbano y el rural, lo que él denominaba «la dialéctica ciudad-campo». La cronología que sobre el comportamiento de la economía castellana propuso rompía con la anteriormente establecida, y sobre sus surcos ha ido superponiendo enmiendas mejorantes toda una generación de historiadores económicos. El tema de las relaciones campo-ciudad era algo sobre lo que volvía de forma reiterada y no sin un cierto tono de desánimo y desencanto, pues había brindado el descubrimiento de la documentación que hacía posible su estudio, los Expedientes de Hacienda de Simancas, y tenía la sensación de no haber sido suficientemente entendida ni atendida su propuesta.

La etapa siguiente, la que discurre en la Universidad Autónoma de Madrid, a cuya cátedra de Historia Económica se trasladó en 1973, fue más bien la del reconocimiento académico y cosecha de honores, tanto nacionales como internacionales, sin que por ello cediera en su actividad docente y menos en la investigadora. Siguió investigando hasta casi el final de sus días. Muy pocos meses antes de morir apareció su último trabajo, «Las finanzas de Carlos V», cuyas pruebas de imprenta tuvimos finalmente que revisar, pues, carente ya de ánimos, más que de fuerzas, iba dilatando su conclusión. En estos años fue invitado por John Elliott al prestigiosísimo y selectivo Institute for Advanced Study de Princeton (1978-1979) y fue nombrado, tras jubilarse, Profesor Emérito de la Universidad Autónoma de Madrid (1986), em- 
pleo que disfrutó, y disfrutamos, hasta octubre del 2003. Recibió también otros reconocimientos académicos: fue nombrado miembro del Consejo de Redacción de The Journal of European Economic History (1974), fue elegido Presidente, primer Presidente, de nuestra Asociación de Historia Económica; fue miembro del Consejo Asesor de esta Revista de Historia Económica (1983), y luego, desde 1992 hasta su fallecimiento, del Patronato de la misma, representando a la Asociación de Historia Económica; recibió el Premio Nacional de Historia (1991) y, asimismo, el de Humanidades y Ciencias Sociales de la Junta de Castilla y León (1992); fue investido Doctor Honoris Causa por las Universidades de Valladolid (1985) y del País Vasco (1988). También fue distinguido con galardones civiles como las Palmes Académiques del Gobierno francés (1983) y la medalla de Alfonso X el Sabio (1987). Pero, para don Felipe, el reconocimiento y distinción que sobresalía por encima de todos era el haber sido elegido académico de número de la Real Academia de la Historia, en la que ingresó en 1990. Fue el honor por él más anhelado y apreciado.

La labor investigadora en esta etapa continúa profundizando en la trayectoria de siempre, pero se pueden advertir algunos matices y variantes. Don Felipe, fiel a la Escuela de los Annales, que no concebía una Historia Económica disociada de la realidad social y política, sabía que, en última instancia, la Historia la hacen los hombres, más precisamente los grupos humanos, que actúan en medio de estructuras e instituciones de diversa naturaleza. Esta prescripción historiográfica había sido siempre atendida por don Felipe, pero en esta etapa se acentúa su cumplimiento y su convicción, hasta el punto de acerar sus críticas contra ciertas derivas que advertía en nuestra disciplina. Con acierto supo identificar a distintos grupos sociales amalgamados por valores e intereses -sugestiva la categoría de «clases intermedias» que él acuñó o aplicó a la Castilla moderna- y advertir sus vaivenes, desplazamientos y postergaciones, al compás no sólo de la coyuntura económica, sino también de los cambios políticos y del manejo de los resortes del poder y de la presión social. En momentos en que la Historia Política de la Edad Moderna, en la que él se inició, estaba experimentando una intensa renovación, fue capaz de asimilar y asumir sus enfoques y resultados como Historia Constitucional para integrarlos con sus propios hallazgos en el área de la economía. Parecería que había completado su periplo académico, volviendo a sus orígenes de historiador de la política, pero tras saldar sus cuentas con aquella historia rancia por la que en principio apostó y que tanto le decepcionó. Para ello tuvo que transitar por la Historia Económica en una versión y enfoque de los que el profesor Ruiz Martín, don Felipe, seguirá siendo faro y guía a través de una obra que de seguro perdurará más que su persona. 
